\title{
College and University Library Buildings: Results of the Questionnaire
}

Mr. Stallings is librarian, North Dakota Agricultural Co.lege, Fargo.

THIS Is another of a series of articles 1 resulting from a questionnaire sent out by the ACRL Buildings Committee. Other articles have appeared in College and occupy a separate main building? Yes: 582 ; No: 846 .

Question No. 2: Give the year of original construction. According to the questionnaire, a total of 573 buildings were built from 184 I-I 95 I.

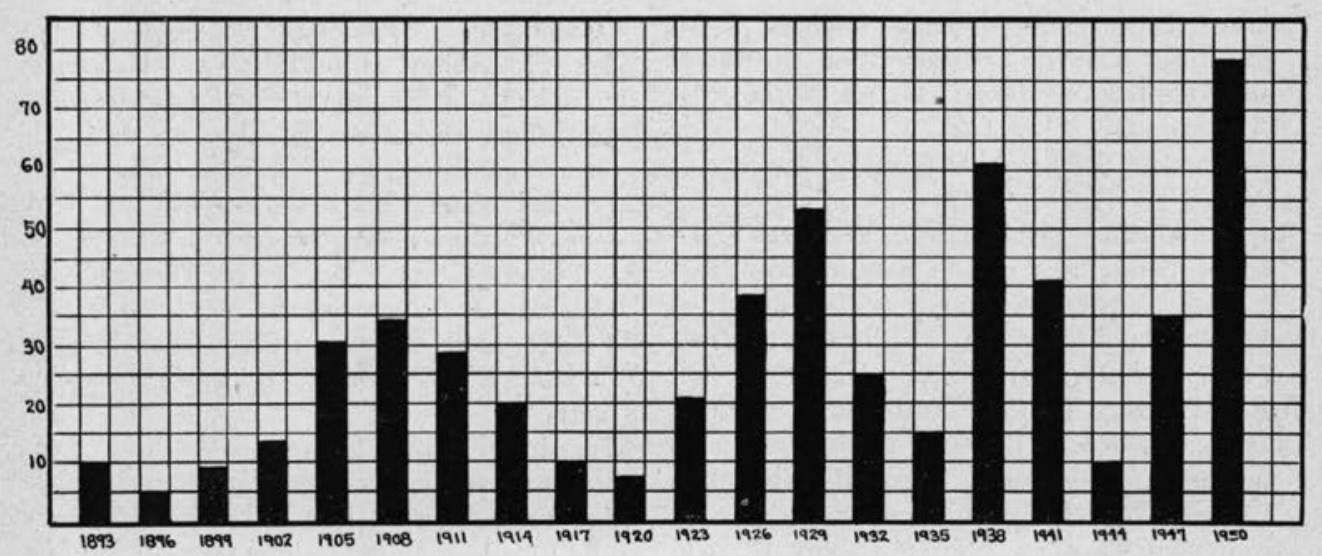

Figure I: Library Buildings Constructed, I891-1950, by 3-year Periods.

Research Libraries ${ }^{1}$ and one more article pertaining to the relationship between seating capacity and size of student body is in process and should be completed during the current year.

This questionnaire was sent to $\mathrm{I}, 860 \mathrm{col}$ lege and university libraries; I,555 replied. Thus, very complete and up-to-date information is available on college and university library buildings.

In this report, complete results are given or reference is made to other articles written as a result of the questionnaire.

The first question was: Does your library

1 October 1950, January and July 1951, and April 1952.

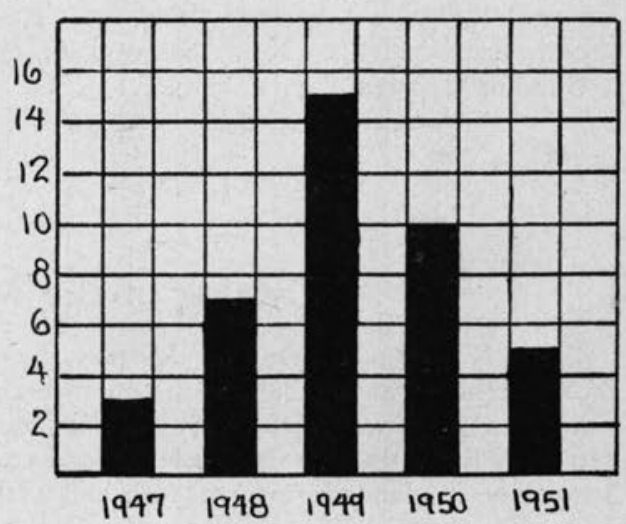

Figure 2: Additions to College and University Library Buildings, 1924-1951, by 2year Periods. 


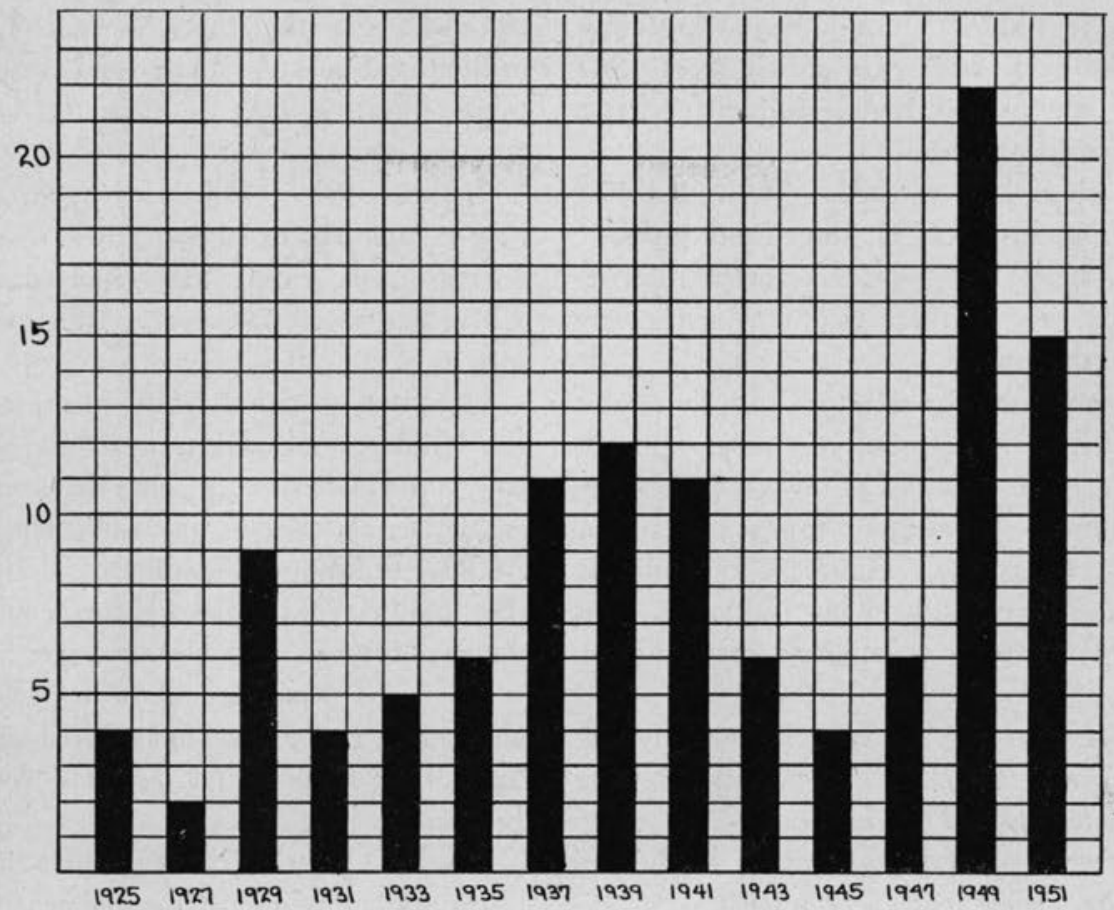

Figure 3: Additions to College and University Library Buildings, 1947-1951.

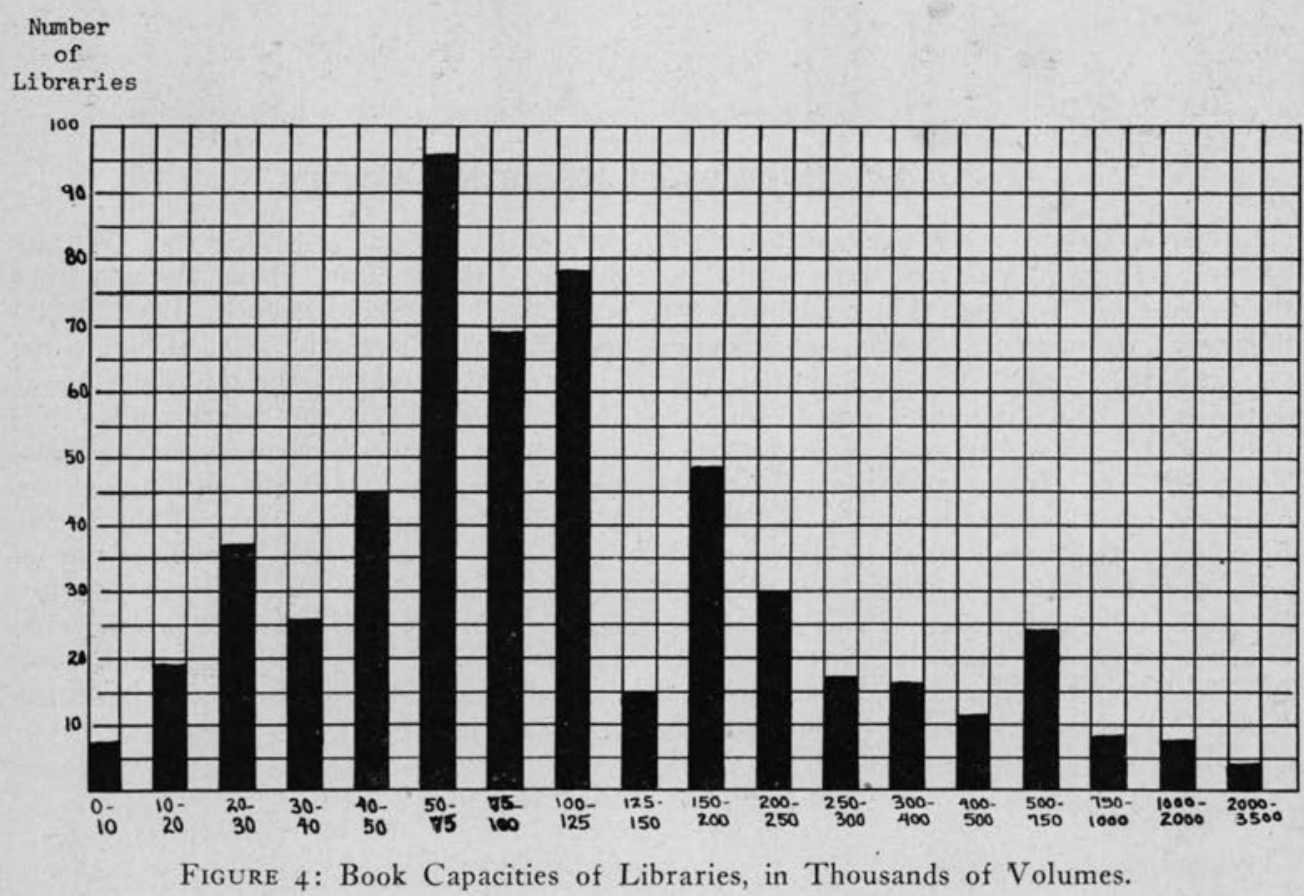

JULY, 1952 
Figure $I$ shows the number of buildings built in each three-year period from I89I to 1950. For example, from, 1948-1950, 78 libraries were built.

Question No. 3 asked: If the building was originally built for some other purpose, check here. - Ninety libraries checked this, so there might be a problem for further study.

Question No. 4 asked: Additions built since then? One hundred thirty eight additions have been built. Figure 2 shows the number of additions for each two-year period, 1924-195I; Figure 3, the number built during each of the last five years. For example, fifteen additions were built in I949.

Question No. 5 stated: How many volumes could your library hold if it were completely filled?

Figure 4 shows the number of libraries and the capacity of the libraries. For example, there are $9 \mathrm{I}$ libraries whose capacity is between 50,000 and 75,000 . There are eleven libraries that report a capacity of one million volumes or over, and thirty-two more libraries have a capacity between 500,000 and $1,000,000$.

Question No. 6 asked: Is your library now completely or almost filled? 267 reported "Yes" and 30r reported "No." These figures are for separate library buildings only.

Questions 7 and 8 relate to the seats in the buildings as compared to the student body, and whether or not the seating is ample, barely ample, or insufficient. The ACRL Buildings Committee is studying this and a report will be forthcoming in the near future.

Questions 9 and ro relate to new buildings before 1960, and was reported on in the April 1952 issue of College and Research Libraries.

Finally, Question No. II shows that II 4 libraries plan an addition in the near future, and 28 plan to construct or add a department library.

\section{New LC Albums of Recorded Poetry}

Five new albums of recorded poetry read by the poets themselves have been issued by the Library of Congress. These albums containing 25 double-face, 12 -inch, unbreakable vinylite ( 78 r.p.m.) records, comprise the second series of five albums issued under the title Twentieth Century Poetry in English. The first series was issued in 1949. Prepared under a special grant from the Bollingen Foundation, the second series includes poems by Robert Frost, Archibald MacLeish, Stephen Spender, Theodore Roethke, Muriel Rukeyser, William Empson, Conrad Aiken, Robert Lowell, Leonie Adams, Elizabeth Bishop, Richard Blackmur, Howard Baker, Marya
Zaturenska, Delmore Schwartz, Wittner Bynner, Herbert Read, Phelps Putnam, John Barryman, Horace Gregory, Janet Lewis and Robert Fitzgerald. Available either singly or in the albums, the recordings are an important guide to the interpretation and meaning of individual poems since they capture the poet's emphasis and shading of tone. A leaflet containing the texts of the poems, biographical notes, and a bibliography is provided with each record, and a catalog listing all of the records available in this series may be obtained for 5 cents from the Recording Laboratory, Library of Congress, Washington 25 , D.C. 